\title{
Principles for knowledge co-production in sustainability research
}

\author{
Albert V. Norström ${ }^{1 \star}{ }^{1 \star}$, Christopher Cvitanovic ${ }^{2,3}$, Marie F. Löf $\oplus^{4}{ }^{4}$, Simon West ${ }^{1}{ }^{1,5,6}$, Carina Wyborn $(1)$,8, \\ Patricia Balvanera ${ }^{9}{ }^{9}$, Angela T. Bednarek ${ }^{10}$, Elena M. Bennett ${ }^{11}$, Reinette Biggs ${ }^{1,12}$, Ariane de Bremond ${ }^{13,14}$, \\ Bruce M. Campbell ${ }^{15}$, Josep G. Canadell ${ }^{10}{ }^{16}$, Stephen R. Carpenter ${ }^{17}{ }^{17}$, Carl Folke ${ }^{1018}$, \\ Elizabeth A. Fulton $\mathbb{1}^{3,19}$, Owen Gaffney ${ }^{1,20}$, Stefan Gelcich ${ }^{\mathbb{1}}{ }^{21}$, Jean-Baptiste Jouffray ${ }^{1,22}$, \\ Melissa Leach ${ }^{23}$, Martin Le Tissier $\mathbb{B}^{24}$, Berta Martín-López $\mathbb{B}^{25}$, Elena Louder ${ }^{26}$, Marie-France Loutre $\mathbb{B}^{27}$, \\ Alison M. Meadow ${ }^{28}$, Harini Nagendra $\mathbb{C}^{29}$, Davnah Payne ${ }^{30}{ }^{30}$, Garry D. Peterson ${ }^{10}$ ', \\ Belinda Reyers $\mathbb{1}^{1,31}$, Robert Scholes ${ }^{32}$, Chinwe Ifejika Speranza ${ }^{33}$, Marja Spierenburg ${ }^{34,35}$, \\ Mark Stafford-Smith ${ }^{36}$, Maria Tengö ${ }^{(1)}$, Sandra van der Hel ${ }^{13}{ }^{37}$, Ingrid van Putten ${ }^{3,19}$ and \\ Henrik Österblom (1) 1
}

Research practice, funding agencies and global science organizations suggest that research aimed at addressing sustainability challenges is most effective when 'co-produced' by academics and non-academics. Co-production promises to address the complex nature of contemporary sustainability challenges better than more traditional scientific approaches. But definitions of knowledge co-production are diverse and often contradictory. We propose a set of four general principles that underlie highquality knowledge co-production for sustainability research. Using these principles, we offer practical guidance on how to engage in meaningful co-productive practices, and how to evaluate their quality and success.

H uman domination of the biosphere has led to substantial gains in human welfare and economic development, but simultaneously threatens the planetary conditions that underpin societal wellbeing and prosperity ${ }^{1-3}$. Emerging challenges, including water scarcity, food security issues and biodiversity loss, are intractable, interconnected and influenced by a range of crossscale drivers and complex feedback mechanisms ${ }^{4}$. These challenges, and attempts to address them, involve multiple groups of people with different needs and interests and are beset by social, political and administrative uncertainty ${ }^{5}$.

Researchers and practitioners alike are turning to knowledge co-production as a promising approach to make progress in this complex space. Conceptually, knowledge co-production is part of a loosely linked and evolving cluster of participatory and transdisciplinary research approaches that have emerged in recent decades. These approaches reject the notion that scientists alone identify the

\footnotetext{
'Stockholm Resilience Centre, Stockholm University, Stockholm, Sweden. ${ }^{2}$ Australian National Centre for the Public Awareness of Science, Australian National University, Canberra, Australian Capital Territory, Australia. ${ }^{3}$ Centre for Marine Socioecology, University of Tasmania, Hobart, Tasmania, Australia. ${ }^{4}$ Baltic Sea Centre, Stockholm University, Stockholm, Sweden. ${ }^{5}$ Fenner School of Environment and Society, Australian National University, Canberra, Australian Capital Territory, Australia. ${ }^{6}$ Northern Institute, Charles Darwin University, Darwin, Northern Territory, Australia. ${ }^{7}$ Luc Hoffmann Institute, IUCN Conservation Centre, Gland, Switzerland. ${ }^{8}$ W.E. Frankie College of Forestry and Conservation, University of Montana, Missoula, MT, USA. ${ }^{9}$ Instituto de Investigaciones en Ecosistemas y Sustentabilidad, Universidad Nacional Autónoma de México, Morelia, Michoacán, Mexico. ${ }^{10}$ The Pew Charitable Trusts, Washington, DC, USA. "Department of Natural Resource Science and McGill School of Environment, McGill University, Montreal, Quebec, Canada. ${ }^{12}$ Centre for Complex Systems in Transition, Stellenbosch University, Stellenbosch, South Africa. ${ }^{13}$ Centre for Development and Environment, Global Land Programme, University of Bern, Bern, Switzerland. ${ }^{14}$ Department of Geographical Sciences, University of Maryland, College Park, MD, USA. ${ }^{15}$ CGIAR Research Program on Climate Change, Agriculture and Food Security, International Center for Tropical Agriculture, University of Copenhagen, Copenhagen, Denmark. ${ }^{16} \mathrm{Global}$ Carbon Project, CSIRO Oceans and Atmosphere, Canberra, Australian Capital Territory, Australia. ${ }^{17}$ Center for Limnology, University of Wisconsin-Madison, Madison, WI, USA. ${ }^{18}$ The Beijer Institute, Royal Swedish Academy of Sciences, Stockholm, Sweden. ${ }^{19} \mathrm{CSIRO}$ Oceans and Atmosphere, Hobart, Tasmania, Australia. ${ }^{20}$ Potsdam Institute for Climate Impact Research, Potsdam, Germany. ${ }^{21}$ Departamento de Ecología, Center of Applied Ecology and Sustainability, Center for the Study of Multiple-Drivers on Marine Socio-Ecological Systems, Pontificia Universidad Católica de Chile, Santiago, Chile. ${ }^{22} \mathrm{Global}$ Economic Dynamics and the Biosphere Academy Programme, Royal Swedish Academy of Sciences, Stockholm, Sweden. ${ }^{23} \mathrm{Institute}$ of Development Studies, University of Sussex, Brighton, UK. ${ }^{24}$ Future Earth Coasts, MaREl Centre for Marine and Renewable Energy, Environmental Research Institute, University College Cork, Cork, Ireland. ${ }^{25}$ Faculty of Sustainability, Leuphana University of Lüneburg, Lüneburg, Germany. ${ }^{26}$ School of Geography and Development, University of Arizona, Tucson, AZ, USA. ${ }^{27}$ PAGES International Project Office, Bern, Switzerland. ${ }^{28}$ Institute of the Environment, University of Arizona, Tucson, AZ, USA. ${ }^{29}$ School of Development, Azim Premji University, Bangalore, India. ${ }^{30}$ Global Mountain Biodiversity Assessment, University of Bern, Bern, Switzerland. ${ }^{31}$ Department of Conservation Ecology, Stellenbosch University, Stellenbosch, South Africa. ${ }^{32}$ Global Change Institute, University of the Witwatersrand, Johannesburg, South Africa. ${ }^{33}$ Institute of Geography, University of Bern, Bern, Switzerland. ${ }^{34}$ Radboud University Nijmegen, Nijmegen, the Netherlands. ${ }^{35}$ Stellenbosch University, Stellenbosch, South Africa. ${ }^{36} \mathrm{CSIRO}$ Land and Water, Canberra, Australian Capital Territory, Australia. ${ }^{37}$ Copernicus Institute of Sustainable Development, Utrecht University, Utrecht, the Netherlands. *e-mail: albert.norstrom@su.se
} 


\section{Box 1 | The history of knowledge co-production}

Knowledge co-production is part of a loosely linked and evolving cluster of approaches, including participatory research, mode 2 science, interactive research, civic science, post-normal science, transdisciplinary and joint knowledge production, action research, translational ecology and engaged scholarship that have become increasingly prominent during the past 40 years ${ }^{84-87}$. Such new forms of knowledge production began to emerge as a response to the complexity and social relevance of emerging challenges, including environmental concerns, economic development and social upheaval. They are context-driven, problemfocused and require the engagement of multiple disciplines.

In parallel, an expansion of the involvement of non-academic actors in knowledge generation and research activities has taken place. Participatory research, for example, has its roots in the work of Kurt Lewin ${ }^{88}$, and developed further across multiple fields in the 1970s, such as research in industrial organization ${ }^{89}$, adaptive environmental management and assessment ${ }^{90}$, as well as through studies of oppressed communities in developing regions ${ }^{91}$. Postnormal science introduced the idea of participation through an extended peer community to deal with societal problems characterized by high uncertainties and high decision stakes ${ }^{85}$. Further development of this new state of science, that stressed mission-oriented problem-solving was articulated under the name of 'mode 2' knowledge production ${ }^{84}$.

The concept of co-production encompasses all of these ideas. One of the first uses of the term 'co-production' was by Elinor and Vincent Ostrom in the 1970s as a way to describe how public services were not simply provided by government agencies to society in a one-way flow, but rather were a distributed, collaborative product of society as a whole. Ostrom introduced the idea of citizens as 'co-producers of public services' to demonstrate that the provision of basic public services like policing relied on both police (to investigate crimes and arrest suspects) and citizens (to report crimes and share information $)^{92}$. The language of co-production spread quickly within the field of public administration, and currently encompasses both state-initiated (top-down) and more radical social-movement (bottom-up) initiated processes ${ }^{93}$.

As the notion of knowledge co-production has gained popularity in sustainability research, two broad approaches have emerged. The first, labelled 'normative', is more pragmatic and regards co-production as a deliberate collaboration between different people to achieve common goals ${ }^{94,95}$. The second, referred to as 'descriptive', examines how science and society constantly shape each other in expected but also unexpected ways. This approach regards all knowledge as being continually shaped and co-produced by the current social order ${ }^{96}$. Despite some tensions among the approaches they often merge with each other in various ways ${ }^{11,97}$. For instance, many approaches to knowledge co-production begin with a descriptive account (for example, the world is complex, science and society are constantly shaping each other), and use this as the basis for a normative account of what should occur (for example, science-society interactions should be developed in terms of participation/inclusion and acceptance of the validity of multiple perspectives). issue, research the problem, and then deliver knowledge to society, in favour of more interactive arrangements between academic and non-academic actors (Box 1). Over the past decade, knowledge co-production has shifted from niche areas of scientific practice towards the mainstream ${ }^{6}$. Within international science and policy fora there is a growing expectation that shifting towards co-production will enable science to have greater impact on sustainable development outcomes. This has led to substantial commitments to knowledge co-production. Examples include the strategic plans for sustainability research in countries such as Switzerland, Australia, the United Kingdom and Germany; the decadal strategic plan of the US Global Change Research Program ${ }^{7}$ and the focus of international research networks such as the Programme on Ecosystem Change and Society ${ }^{8}$, the Global Land Programme ${ }^{9}$ and Future Earth ${ }^{10}$. However, these commitments outpace the development of guiding definitions of what knowledge co-production is and frameworks to assess its quality or success. Indeed, while the term has become commonplace in sustainability research, the ways in which it is conceptualized and implemented are highly variable ${ }^{11}$. This contributes to the creative use of the concept, but also limits the ability to assess and learn from the outcomes and thus improve practice.

In this Perspective, we draw upon our collective experiences working within diverse sustainability co-production processes-as well as recent theory and empirical practice from fields such as participatory research and transdisciplinary research-to propose a definition of knowledge co-production for sustainability research. We identify four principles that underpin high-quality co-production that can guide researchers, practitioners, programme managers and funders seeking to engage in co-produced sustainability research. We continue by presenting a set of considerations for monitoring and evaluating how these principles are put into practice. Finally, we identify key advances that will improve the abilities of researchers, practitioners and funders to engage in meaningful co-productive practices and address the sustainability challenges of the Anthropocene.

\section{Four principles of knowledge co-production}

Based on the literature and experiences and perspectives of leading researchers and practitioners engaged in knowledge co-production around the world (for methodological details, see Supplementary Information), we define knowledge co-production in the context of sustainability research as:

'Iterative and collaborative processes involving diverse types of expertise, knowledge and actors to produce context-specific knowledge and pathways towards a sustainable future.'

We describe co-production processes as 'iterative' because we find that there is no single approach for success, and 'collaborative' because the act of engagement across domains and disciplines can be as important for the pursuit of sustainability as the production of knowledge. Compared to disciplinary research processes, knowledge co-production extends from a collaborative stage of problem framing and trust building, through knowledge generation, to a phase of exploring the practical impacts of the process. Our definition emphasizes that co-production processes produce more than just knowledge; they develop capacity, build networks, foster social capital, and implement actions that contribute to sustainability.

The high context-specificity associated with knowledge co-production precludes a more prescriptive definition. However, we propose four general principles that contribute to high quality co-production for sustainability. Specifically, we suggest that processes should be: (1) context-based; (2) pluralistic; (3) goal-oriented; and (4) interactive (Fig. 1). We explore these principles in more detail in this section and describe three case studies of knowledge co-production to explicitly highlight some of the practical nuances in applying the principles (Boxes 2-4). We recognize that there is some overlap between the principles. Even though some principles underpin the application of others, they are deliberately not presented in a sequential manner.

(1) Context-based. Co-production processes should be considered and situated within the particular social, economic and ecological 


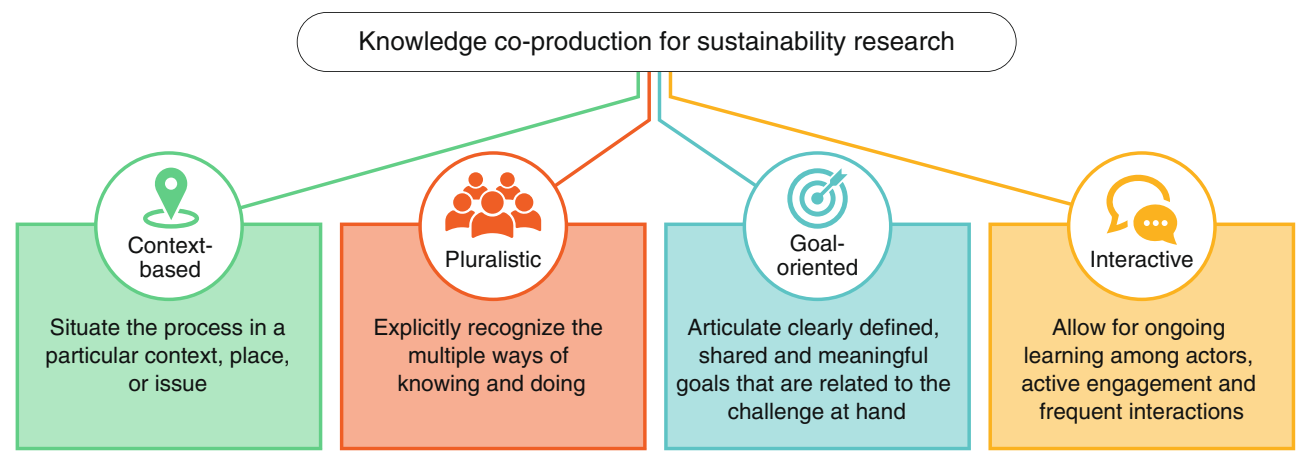

Fig. 1 | Principles for knowledge co-production in sustainability research. High-quality knowledge co-production for sustainability should be contextbased, pluralistic, goal-oriented and interactive.

\section{Box 2 | Future-proofing conservation in Colombia}

This project involved researchers, civil society, local practitioners and conservation advisers to develop new ways of understanding and managing Colombian protected areas in the face of ongoing ecological change. The process was catalysed by the Luc Hoffmann Institute, a boundary organization that partners closely with World Wide Fund for Nature (WWF) offices around the world.

The project was situated within the context of the REDPARQUES Declaration, a commitment made by 18 Latin American countries at the 2015 United Nations Climate Change Conference in Paris to integrate protected areas into climate mitigation and adaptation. This provided a political window of opportunity, together with national processes such as the development of Colombia's Nationally Determined Contribution (NDC) and a process to revise the Colombian protected area planning and management framework (PAMF). The project built on a longstanding relationship between WWF Colombia and the Colombian protected area agency around climate change. The close collaboration with WWF enabled an international research team who did not speak Spanish, nor had prior history of working in Colombia, to participate in this project.

Project goals were co-developed over a one-year period, building on the existing work of individuals and organizations within the team. This created a co-dependency within the project goals, whereby policy and research objectives could not be realized in isolation. The project would have been designed very differently were it simply a policy project or a research project and at times there were challenges for both researchers and practitioners to appreciate the complexities of each other's worlds.

Then followed a two-year co-production process (2015-2017) where the team developed and piloted a methodology in two landscapes. Some elements of interaction were made difficult by the dispersed locations of the project team (Colombia, United Kingdom, Switzerland and Australia). Regular conference calls helped to support dialogue and biannual face-to-face meetings in Colombia built shared understandings, addressed tensions, and supported progress towards project goals. On reflection, these goals required a degree of interaction and iteration that would be more suited to a project team that was co-located (or at least on the same continent or time zone). This learning suggests that teams should carefully consider project goals in relation to resources and capacities required to develop shared perspectives and activities.

The project attempted to utilize participatory evaluation scorecards to facilitate dialogue and learning. While this tool was often successful, it was sometimes difficult to dedicate sufficient time to complete the scorecard. This points to a tension between the need for reflection, and continuing progress within short time horizons of a project. An external evaluation (that drew on project documentation and interviews) was conducted prior to the project's completion, and missed some of the broader impacts because they had yet to take effect.

While this project faced challenges, it is widely heralded by partners as a success. The methodology has been completed ${ }^{98}$, and elements of it are now being used, adapted and further developed by project partners. Four factors were critical to the project's success: (1) alignment between project goals and the individual motivations and organizational incentive structures of participants; (2) the political window of opportunity created by Colombia's NDC and the REDPARQUES Declaration and the revision of the PAMF; (3) iterative and flexible methodology; and (4) the commitment and respect for diverse perspectives within the team. contexts in which they are embedded, and the associated confines and opportunities of the surrounding circumstances. A co-production process can be place-based, but 'context' is not synonymous with 'local'; it could be national, regional, global or even scale-agnostic, but restricted to a defined set of issues. Contextbased co-production also means taking into account the different needs, interests and beliefs of the different social groups who are invested in or affected by the challenge at hand ${ }^{12,13}$.

Situating a co-production process involves asking questions about how a particular challenge has emerged, and how changing circumstances are likely to influence the work (Boxes 2-4). Such questions include: who will be impacted or affected by the process and its outcomes? Who has the power to enable or constrain action?
How will policy, regulatory, institutional and cultural factors shape the process and the realization of desired outcomes? For example, the co-production of drought information systems by Native American communities and researchers in the US Southwest was shaped by financial (for example, no investments for more weather stations) and technological factors (for example, slow Internet connections and limited data-handling infrastructure), which resulted in context-specific solutions of combining local observations with a structured monitoring framework ${ }^{14}$. Identifying policy windows or entry points within a given context can provide a tangible starting place to consider how a knowledge co-production process can contribute to the pre-existing goals and objectives of partners (Box 2). It is also critical that co-production processes are described 


\section{Box 3 | Alternative livelihoods in Papua New Guinea}

The borderland region of the South Fly, Papua New Guinea (PNG) is one of the poorest regions in the world. This project wanted to understand how sustainable fisheries and community well-being in the region could be assured while at the same time reducing illegal and unsustainable activities, such as illegal trade in fisheries supply chains ${ }^{99}$.

Community leaders and non-governmental organizations (NGOs) were instrumental in connecting a multi-cultural group of researchers (from Australia, Indonesia and PNG), to managers (mainly from the PNG fisheries agency), local translators and interviewers, actors in the fisheries sector and supply chain (fishers, middlemen/women, buyers and exporters), and community members. Project ownership was partly achieved through early involvement of local grassroots NGOs and community leaders in collaboratively designing the research and developing agendas for meetings and workshops.

Situating this project was not straightforward, given the remote and economically disadvantaged nature of PNG, where education levels and literacy rates are very low, and local cultural traditions are strong. The project benefitted from prior relationships; the continuity in the researchers returning to the area multiple times per year over at least five years (for different projects and purposes) meant they became familiar faces and led to more trust and consequent engagement. Because the project focused on the sensitive issue of illegal trade, this trust also reduced the fear of being prosecuted or being exposed to adverse project consequences. Aside from familiarity, support for the project was created through productive and respectful connections to key individuals (community 'gatekeepers') which was essential for gaining representative community interactions.

A diverse team with a good mix of ages, seniority, gender and cultural backgrounds was key to encouraging a similar level of pluralism to be reflected in the actors involved in co-production. For instance, in a traditional society like PNG some aspects of decision making are gender specific, and females may not traditionally participate. They are nevertheless key to ensure the workability of a co-produced solution. Access to societal groups which are more difficult to engage, was facilitated by female researchers connecting with females in the community who subsequently transferred the perceived trustworthiness of project team members to local community members. On the flipside, co-production could have been derailed if trust was broken by inadequate knowledge of local customs and taboos. Sensitivity around getting the right mix of people in the room was facilitated by having separate aspects of co-production in gender safe spaces. Taking a gender-sensitive approach revealed some important gender-related consequences in marine product trade. In the co-production process, it was also important to be sensitive to different learning methods. Simple printed infographics provided important leverage points for discussion and co-production of results.

Ultimately, solutions to local fisheries and supply chain issues were co-produced with local PNG fishermen and women, middlemen/women and traders. Twelve solutions were identified drawing on different knowledge systems, perspectives and understanding of the key issues. This approach has led to increased local understanding of complex supply chain links and present trade dynamics. The belief that the project could bring tangible changes to the communities (in the long term) meant continued and enthusiastic participation. Moreover, the lengthy and continuous involvement of project proponents with local people in the communities, their connections to several institutions and local NGOs meant they were well informed of extant local issues and potential points of conflict.

\section{Box 4 | Managing ecosystem services in Canada}

The Montérégie Connection project focused on improving landuse management for the provision of multiple ecosystem services in the Vallée-du-Richelieu Municipalité Régionale de Comté (MRC), a $75 \mathrm{~km}^{2}$ regional governance body involving 13 towns southeast of Montréal. The project was developed by a pluralistic collaboration of researchers from multiple departments at McGill University, alongside members of the boundary organization Centre de la Nature de Mont Saint Hilaire $(\mathrm{CN})$ and a variety of local actors, including farmers, mayors and other government representatives, land-use planners and $\mathrm{NGOs}^{100}$.

The process was situated in a context in which political action, including Montréal's commitment to the Aichi target of preserving $17 \%$ greenspace, was pulling towards recognition of the value of greenspace. Local land-use planners recognized that the science needed to make good decisions about which $17 \%$ to preserve was not as coherent as they would like. This provided an entry point and a policy window that eased the process of agreeing on an overarching goal, despite the pre-existing divergence of goals and objectives of partners.

However, coming to an agreed-upon set of goals required the whole first year of the project to be dedicated to working interactively with the community to determine project goals that were both scientifically compelling and useful for them. Most of those interactions were spearheaded by the $\mathrm{CN}$, who helped researchers understand how land-use planning decisions were made in the region, and to identify key actors to engage in the process. Actors were asked about their concerns for the future of the region during small workshops or one-on-one meetings.

The project continued with four years of field research, and research into historical land-use change and provision of ecosystem services in the past. This was followed by community-based scenario development and modelling of future ecosystem service provision under each set of scenarios. Researchers interacted frequently with landowners on whose property they were undertaking fieldwork, met with other formal partners (co-signatories on the grant that funded the work) annually or semi-annually, and convened a larger group of local actors at least annually. At those meetings, feedback on the project progress was collected, helping to adjust the project as it progressed to make sure it was meeting contextual needs and goals. The Montérégie Connection project received the Alice Johannsen award for contribution to the protection of local nature, and many participants spoke about a change in their attitude towards landscape sustainability and ecosystem services as a result of having participated in the project.

One of the critical factors in the success of the Montérégie Connection project was the strong relationship with the boundary organization CN. For 15 years prior to the start of the project, the $\mathrm{CN}$ had worked to raise public awareness of the importance and vulnerability of the local natural heritage, focusing on the Mont Saint Hilaire Biosphere Reserve and surrounding communities. The $\mathrm{CN}$ had also been working with researchers at McGill and understood both the scientific process and needs of the scientists working on the project, in addition to the needs of the community. This allowed the $\mathrm{CN}$ to bring both together around a common set of goals. The $\mathrm{CN}$ was also able to foresee many potential issues such as power differentials or political roadblocks which could have stalled the project. 
in contextually relevant language and based on a shared understanding of key concepts and terminology $y^{8}$.

(2) Pluralistic. Co-production of knowledge must explicitly recognize the multiple ways of knowing and doing. Feminist and standpoint theorists, among others, have persuasively argued that all knowledge is inevitably situated and partial ${ }^{15}$, highlighting the practical and ethical importance of ensuring a range of perspectives on a given issue. Achieving pluralistic co-production entails bringing together academics (from different disciplines) and people from other sectors (from for example, government, business, civil society, local and indigenous communities) to generate knowledge and catalyse change. It is important to ensure that those involved represent a range of skills (for example, analysis, translation, synthesis, facilitation and evaluation) and types of knowledge and expertise (for example, experiential, local, traditional, academic and official). This diversity generates an enriched understanding of the ecological, political and technical aspects of a sustainability challenge ${ }^{16}$. Moreover, research suggests that under the right conditions, knowledge outcomes are enhanced by including various other dimensions of diversity, such as gender, ethnicity, age and nationality ${ }^{17}$.

Pluralistic processes do pose risks and challenges not present in more traditional research practices, and can increase transaction costs ${ }^{18-20}$. For example, the convenor of a co-production process faces the task of assembling an appropriately broad coalition of relevant actors, while keeping the process manageable within practical and strategic limits ${ }^{21,22}$ (Box 3). Techniques such as stakeholder mapping ${ }^{23}$ and social network analysis ${ }^{24}$ can help address this challenge. A step-wise approach to participation can reduce potential points of conflict or allow for some facilitating steps to be undertaken before a broader group is engaged (Box 3). Preferably, the coalition will include the relevant expertise, experience and interests that are needed to tackle the sustainability challenge in a way that provides solutions and contributes to the related scientific body of knowledge ${ }^{12}$. Another challenge relates to power dynamics in participatory processes. A failure to sufficiently engage with power imbalances lessens the quality of the engagement and process outcomes, and can derail and undermine the entire exercise ${ }^{25}$. Asymmetrical power relations can prevent some actors from engaging in knowledge co-production ${ }^{26}$ and will reproduce knowledge hierarchies, in which certain knowledge and expertise are seen as being more legitimate than others ${ }^{27,28}$. Tools like the 'Power Cube' (www.powercube.net) can help participants to map the different ways power manifests itself ${ }^{29}$.

While helpful, these tools will not provide easy solutions and in the real world choices often have to be made quickly on the basis of practical judgement. Systematically reflecting on and reviewing the process is vital for unearthing the visions, understandings and values of the actors involved ${ }^{27,28,30}$, identifying positions of power and sources of inequity, and developing ameliorative strategies ${ }^{31}$. There is also growing evidence that pluralistic processes can be improved by individuals, teams or organizations that possess broad knowledge across multiple domains (for example, science, policy and practice) and skills that foster learning, trust and conflict resolution. These roles have been variously referred to as boundary spanners/organizations $^{32,33}$ (Box 4), bridging organizations ${ }^{34}$, knowledge brokers ${ }^{35}$ and epistemediators ${ }^{36}$.

(3) Goal-oriented. Knowledge co-production for sustainability is problem-focused and benefits from clearly defined and meaningful goals shared among participants (Box 3). It is important to develop a collective understanding among all participants of the challenge(s) at hand, as well as an agreed measure of success (that is, the overarching goal). Success can take many forms, and includes changes in policies and practices, changes in attitudes and perceptions, or the creation of new relationships and networks of collaboration ${ }^{37}$. Once overarching goals are established, participants should work together to identify meaningful milestones (that is, stepping-stone goals) to achieve and monitor progress. This facilitates learning, increasing the likelihood of achieving the desired broad-scale outcomes ${ }^{38}$ and reducing the potential for hidden agendas to undermine the progress and the legitimacy of co-production processes ${ }^{39}$. As in transdisciplinary research, sequenced milestones should be identified and revised in iterative processes through which the different resources, aims and values at stake are negotiated and discussed ${ }^{40}$. It is important to recognize that there are often multiple possible pathways to reach an agreed goal ${ }^{41}$.

When setting goals and milestones, it is important to carefully avoid the trap of focusing only on what is measurable ${ }^{42}$. The complexity of the contexts in which co-production processes typically take place makes it difficult to draw direct causal relations between actions and outcomes. Moreover, important outcomes, such as increased agency of previously marginalized actors, are difficult to measure, not the least because such outcomes might only become visible over time and are therefore not captured in the timescale of a project ${ }^{12}$. Finally, recognizing that visions and goals often evolve during a project, and that goals are sometimes contested, it is essential to collectively revisit the goals regularly in an adaptive approach and allow for iteration and reflexivity. A 'theory of change' that generates a hypothesis and describes assumptions about how a set of activities will contribute to a desired change can be used to develop a shared understanding of goals, objectives, metrics for success and the design of co-production processes ${ }^{43}$.

(4) Interactive. High-quality co-production requires frequent interactions among participants to occur throughout the process, extending from collaboratively framing and designing the research agenda, to conducting the research, and jointly using and disseminating the knowledge generated. It is critical to avoid token participation (for example, passive engagement at the onset or completion of a project, with one-way communication flows) and instead create active engagement through frequent interactions and repeated conversations ${ }^{44}$. A growing body of literature sheds light on how the amount, timing and type of interactions influence the quality of knowledge co-production processes ${ }^{45,46}$.

High levels of participant interaction throughout a co-production process nurture ongoing learning among participants ${ }^{39}$ and can build trust through dialogue. Interaction also increases the likelihood that the resulting knowledge is perceived by participants and other end-users as credible (scientifically robust arguments and outputs), salient (relevant to user needs), and legitimate (the extent to which the information is perceived as fair and respectful of all actors). This makes the knowledge more likely to be incorporated into decision-making processes $^{8}$, and increases the chances that the knowledge produced meets specific needs and expectations ${ }^{45}$ (Box 2). Finally, sharing experiences, ideas and values through frequent interactions can facilitate collective action ${ }^{47}$, which is critical to address sustainability challenges that are mired in uncertainty, change and surprise ${ }^{42}$.

\section{Assessing knowledge co-production}

We have suggested that high-quality knowledge co-production is context-based, pluralistic, goal-oriented and interactive. How these principles are put into practice will differ depending on the specific challenge at hand, the actors involved, the social and political contexts, and the scale of the project. The principles are not a definitive list, and we hope that they serve as a stimulus for further discussion and their continued refinement. Improving the practice of knowledge co-production also requires better monitoring and evaluation of co-production practices, and in particular practices that can capture complexity and manage for emergent outcomes ${ }^{42,48}$. 
Co-production is founded on the assumption that the relationships between science, policy and practice are complex, multi-pathway and nonlinear; thus, evaluation frameworks need to align with these assumptions. Monitoring and evaluation will also need to account for different conceptions of 'success' among participants and projects. For example, knowledge co-production may be pursued as a way to enhance the legitimacy of research outcomes, to ensure the implementation of scientific knowledge in society, or in recognition of the limits of scientific expertise and the value of complementary perspectives ${ }^{10}$. In search of such approaches, we turn to recent work on the evaluation of research impact ${ }^{38,49}$ and transdisciplinary practice ${ }^{50-54}$.

Impact is conceptualized and defined in many different ways. For some, ultimate impact is changes in ecosystem health ${ }^{55}$, societal change ${ }^{54}$ or changing peoples' lives ${ }^{56}$. Others break impact down into components or dimensions such as research quality, research relevance, stakeholder knowledge and stakeholder practices ${ }^{57}$. Wiek et al. ${ }^{58}$ divide impacts into direct and indirect effects, to incorporate intangible impacts such as building networks and capacities, alongside the development of more concrete products and outputs. Pitt et al. ${ }^{59}$ identify a discrepancy between processes geared towards producing high-quality research outputs, versus those focused on creating changes in policy and practice, or those aiming at enabling or informing decision making processes. Within this literature, it is clear that all approaches assessing research impact are underpinned by particular philosophical assumptions ${ }^{60}$, and that there is no 'best procedure ${ }^{51}$.

Within transdisciplinary research, the articulation of guiding principles $^{12,13}$ has led to a more nuanced approach to evaluation ${ }^{51,61}$. For example, several studies have used the degree of stakeholder participation, information flow and levels of collaboration across the entire transdisciplinary research process to establish analytical frameworks ${ }^{62}$. Similarly, evaluations of different transdisciplinary research efforts have allowed for the identification of key factors supporting successful practice; for example, the establishment of communities of research and practice where participants can build mutual trust, interact with different knowledge systems, and jointly develop a shared understanding of the problem at hand ${ }^{63}$. Others present principles of quality drawing from the credible, salient, legitimate criteria ${ }^{53-55}$ and then present indicators for evaluation within those. Wickson and $\mathrm{Carew}^{52}$, for example, present the following principles for evaluating socially responsible innovation: socially relevant and solution oriented; sustainability and future scanning; diverse and deliberative; reflexive and responsive; rigorous and robust; creative and elegant; honest and accountable. The authors then present a rubric with ranges of quality from 'exemplary' to 'routine'. Still other scholars arrange indicators into categories of some variation of 'impact dimension,' including context, process, outcome and impact ${ }^{48}$; or research problem, research process and research results ${ }^{64}$.

Across these approaches to evaluation, most include metrics that focus on the process, outputs, outcomes and impacts of the co-production or transdisciplinary research process. Complexityoriented evaluation frameworks emphasize the importance of learning and change over time, and focus on evaluating the quality of processes, relationships and networks ${ }^{48,59}$. We build on these approaches to identify critical aspects of evaluation strategies for context-based, pluralistic, goal-oriented and interactive knowledge co-production. As with our definition and principles, our guidance for monitoring and evaluation is necessarily broad given the context-specificity of all co-production processes, and is intended to be illustrative rather than an exhaustive list. While monitoring and evaluation of co-production faces many practical challenges, it should not require a disproportionate share of resources or overburden participants. The main purpose of monitoring should be to improve the ongoing process. This requires formative evaluation (that is, evaluation that is performed while co-production is in progress) conducted by an extended peer group comprising experts from both science and practice. Such iterative learning also enables the subsequent steps and phases to be reshaped if necessary ${ }^{12}$.

Assessing the context-based principle. Monitoring and evaluation of context-based quality will focus on the degree to which a co-production process is effectively situated within a particular place, set of relationships or a particular issue. For example, did the request for co-production originate from an actor already encountering the problem addressed, such as a community organization or government department? Are the goals of the co-production process linked to the existing priorities and activities of partners directly working in the particular context? Is the process utilizing, building upon and strengthening existing skills and relationships between participants already working in the context? Are the skills and outputs (for example, co-produced solutions) developed during the process still being used and implemented by the community of participants after the initial project is finished ${ }^{18}$ ?

It is vital that this evaluation is itself conducted according to concepts and language relevant for the place, issue and participating actors. Participatory evaluation frameworks and methods are useful for ensuring that the terms of assessment are negotiated by the actors involved ${ }^{65}$. Such approaches help to capture the true value of a co-production process for those working within the particular context or issue, reveal unexpected impacts of the work and prompt the articulation of new context-specific projects and knowledge needs.

Assessing the pluralistic principle. Metrics of pluralistic quality will capture the different elements of diversity within a co-production process. This may include simple measures of inclusiveness that capture the involvement of actors across multiple axes (for example, disciplines, sectors, countries/regions, gender and age) and procedural justice (for example, number of contributions by different types of actors). It may also include considering the degree to which the process enables participants to build trust and develop shared perspectives and understandings ${ }^{63}$, and potentially more complex metrics that assess diversity in mental models and knowledge systems ${ }^{66}$.

While such quantitative indicators are important, they cannot capture the full breadth and depth of a pluralistic process ${ }^{67}$. Evaluating this principle will therefore also require qualitative indicators and approaches that capture whether the process is allowing the knowledge and perceptions of different participants to be mobilized and articulated into forms that can be shared with others ${ }^{16}$. Evaluation and assessment methods may include unconventional forms of collecting evidence, such as narrative indicators, written reflections and blogs. For example, video diaries have been shown to be effective when running throughout a co-production process as a form of live evaluation as opposed to participant interviews conducted at the end of a project ${ }^{68}$. Similarly, short, periodic surveys to evaluate the group dynamics of participatory research efforts can ensure the project is on track to meet participants' needs and learning objectives ${ }^{69}$.

Assessing the goal-oriented principle. Evaluation of goal-oriented quality will focus on the degree to which a co-production process enables the articulation, revision and achievement of desired goals, outcomes and impacts. Goals will include both tangible and intangible outcomes. The former can be assessed by metrics that capture if knowledge generated by the process is directly informing management or policy decisions ${ }^{48}$. However, not all co-produced research will necessarily lead to policy impacts. Impacts can be difficult to measure with any certainty, because of the complex linkages between knowledge and action ${ }^{70,71}$ and the long timescales 
over which impacts arise, which make attribution challenging ${ }^{72}$ However, focusing on the goals, for example, building relationships, will help identify appropriate evaluation approaches ${ }^{49}$.

A high-quality co-production process may often lead to less conventional outcomes such as building new understandings, relationships and social networks. While these outcomes may be at the level of individual participants and their understanding, rather than at the scale of an entire social-ecological system, they can pave the way for larger-scale and longer-term changes. Evaluation approaches that measure contribution to change throughout a process can therefore be more appropriate than those focused on direct attribution of cause and effect at the end of a process ${ }^{73}$. It is also critical to develop temporally dynamic approaches that generate rapid feedback and real-time data to enable a project to continually evolve to meet its goals, such as developmental evaluation approaches ${ }^{74}$, and that track impact from short to long term (for example, monthly to decadal $)^{75,76}$. Relevant short-term indicators can include enhanced capacity to address the sustainability challenge and increased attention of non-academic actors or media attention. Medium-term indicators relate to the degree to which the co-production process or its outputs are used by partners or other non-academic actors to inform actions, strategies, policies or practice. Finally, longer-term indicators concern the attainment of social or environmental goals. However, given that longer-term impacts will typically be realized well beyond the life of a project, there is a need to be pragmatic about what can be measured during the process itself. Consideration must also be given to ongoing monitoring following the completion of a co-production process. Tracking progress against indicators that align with the project theory of change enables monitoring against goals at different temporal scales within the project timeframe.

Assessing the interactive principle. Metrics of interactive quality will capture the nature, frequency and quality of interactions between participants in a co-production process. Simple quantitative tools (such as attendance lists and meeting minutes) can be used to measure frequency and timing of encounters. Richer qualitative approaches can be used to assess the quality of interactions, such as interviews and surveys to assess if actors perceive they had equitable opportunities to participate in project activities ${ }^{48}$.

Assessing this principle should also focus on capturing learning, how the perceptions of actors change throughout the process and the degree to which a shared perspective on the problem emerges. The process of interactively engaging in co-production should change how participants view a problem as they learn through inquiry, analysis and the sharing of and triangulation amongst diverse perspectives, and potentially trigger reflexive processes about the kinds of knowledge and action needed to address sustainability challenges. In cases where differences in perspective remain, there should be evidence of respect for the diversity of perspectives. Other indicators could focus on assessing whether the co-production process has resulted in a mutual understanding in the face of differences between actors (for example, through communication that uses a language and terms that can be understood by all actors) and whether criteria of credibility (of different knowledge systems) have been dealt with in a respectful way ${ }^{16}$.

\section{Knowledge co-production in the Anthropocene}

The Anthropocene is the first time in the Earth's history that human activities are influencing the global functioning of the Earth system ${ }^{1}$. Actions occurring over the next decades could significantly influence the long-term trajectory of the Earth system, and potentially lead to conditions that would challenge the existence of human civilization ${ }^{4}$. We conclude by identifying some particular opportunities and challenges for sustainability knowledge co-production within this context.
The intertwined social and ecological dynamics of the Anthropocene mean that local and place-contexts are influenced by multiple drivers at larger scales, and have complex connections to other places. In a globalized world, these drivers (for example, trade, international commodity prices, technological improvements, large-scale land acquisitions, fishing and agriculture) are themselves shaped by a complex array of forces. State power and supranational co-operations (for example, the European Union) coexist alongside powerful multinational corporations. At the same time, research institutions and NGOs increasingly operate at a global scale. However, knowledge co-production processes to date have predominantly involved pluralistic coalitions at a local to regional level between academics and actors from other sectors, such as local or national government representatives, business representatives, local and regional NGOs, and natural resource managers (for example, Boxes 2-4). For sustainability researchers committed to instigating change, this requires considering such cross-scale dynamics, how to engage in co-production, and with whom.

Approaches to knowledge co-production for a sustainable Anthropocene may entail new alliances and more direct engagement with global corporate actors to leverage their unique ability to influence change. For example, Österblom et al. ${ }^{77}$ described an ongoing co-production process where researchers are actively engaging with keystone actors that shape marine ecosystems, to collaboratively develop solutions to ocean sustainability challenges. This process has led to the establishment of a unique global ocean initiative, where science and business collaborate toward the United Nations Sustainable Development Goals (www.keystonedialogues.earth). While emerging forms of co-production may produce remarkable gains, they will bring new risks and potential pitfalls. Engaging with industry can influence perceived scientific credibility and also challenge previously established power dynamics.

We envision a new and significant role of knowledge co-production in the Anthropocene to navigate transformations towards sustainability $^{78}$. Transformations that set us on sustainable trajectories need to happen rapidly, and will require massive social changes (shifts in underlying values, assumptions, cultures and worldviews) coupled to technological progress and biosphere stewardship. Research on socio-technical transitions ${ }^{79}$, social-ecological transformations ${ }^{80}$ and leverage points ${ }^{81}$ suggests that many sustainability interventions applied to date have been easy to make, but with limited potential for transformational change. If knowledge co-production processes are to contribute to the call for deep sustainability transformations ${ }^{78}$, they need to recalibrate goals from dealing with proximal problems and quick fixes, towards more explicitly targeting the underpinning, ultimate drivers of current trajectories.

Deeper leverage points for transformational change include reconnecting people to nature, restructuring institutions, and rethinking how knowledge is created and used in pursuit of sustainability ${ }^{81}$. Inevitably this means that knowledge co-production in sustainability research will require more attention to mechanisms of social change including values, politics and power. Researchers engaged in co-production of knowledge will become partners in value-laden and contested societal change processes. These normative and political dimensions should not be brushed under the carpet, but rather addressed transparently and head on. For example, co-produced research on the emerging global networks addressing interlinked environmental, human and animal healthso-called 'One Health' and 'Planetary Health' agendas-has explicitly explored the hierarchies and power relations between medical, veterinary, ecological and social scientists and policymakers, as well as the gaps between global concepts and locally situated knowledge and practices ${ }^{82}$. Doing so requires an open, deliberative and reflexive attitude of sustainability researchers addressing values and politics in knowledge co-production ${ }^{83}$. 
Finally, we urge for a rapid development of new institutions and incentive structures across the science-business-policypractice spectrum. While co-production has gained currency in recent decades, many researchers still face incentive structures that primarily reward disciplinary science that does not engage with society ${ }^{45}$. At the same time, many practitioners work within organizations that do not incentivize critical reflection, ongoing learning and revision of actions. Moreover, the development of a new social contract based around co-production requires changes among those who have the potential power to reshape institutions. For instance, co-production demands that the scientific community incorporates notions of reflexive practice and multiple knowledges into their working practices. While such shifts may be challenging, they are necessary if co-produced knowledge is to grow fast enough to meet the sustainability challenges presented by a rapidly changing world.

Received: 12 December 2018; Accepted: 12 November 2019; Published online: 20 January 2020

\section{References}

1. Rockström, J. et al. A safe operating space for humanity. Nature 461, 472-475 (2009).

2. Raudsepp-Hearne, C. et al. Untangling the environmentalist's paradox: why is human well-being increasing as ecosystem services degrade? BioScience 60, 576-589 (2010)

3. Nash, K. L. et al. Planetary boundaries for a blue planet. Nat. Ecol. Evol. 1, 1625-1634 (2017).

4. Steffen, W. et al. Trajectories of the Earth system in the Anthropocene. Proc. Natl Acad. Sci. USA 115, 8252-8259 (2018).

5. Cash, D. W. et al. Scale and cross-scale dynamics: governance and information in a multilevel world. Ecol. Soc. 11, 8 (2006).

6. The best research is produced when researchers and communities work together. Nature 562, 7 (2018).

7. Weaver, C. P. et al. From global change science to action with social sciences. Nat. Clim. Change 4, 656-659 (2014).

8. Balvanera, P. et al. Key features for more successful place-based sustainability research on social-ecological systems: a Programme on Ecosystem Change and Society (PECS) perspective. Ecol. Soc. 22, 14 (2017).

9. Verburg, P. H. et al. Land system science and sustainable development of the earth system: a global land project perspective. Anthropocene 12, 29-41 (2015).

10. van der Hel, S. New science for global sustainability? The institutionalisation of knowledge co-production in Future Earth. Environ. Sci. Policy 61, 165-175 (2016).

11. Bremer, S. \& Meisch, S. Co-production in climate change research: reviewing different perspectives. Wiley Interdiscip. Rev. Clim. Change 8, e482 (2017)

12. Lang, D. J. et al. Transdisciplinary research in sustainability science: practice, principles, and challenges. Sustain. Sci. 7, 25-43 (2012).

13. Pohl, C. \& Hadorn, G. H. Frameworks for transdisciplinary research: framework \#1. GAIA - Ecol. Perspect. Sci. Soc. 26, 232-232 (2017).

14. Ferguson, D. B., Masayesva, A., Meadow, A. M. \& Crimmins, M. A. Rain gauges to range conditions: collaborative development of a drought information system to support local decision-making. Weather Clim. Soc. 8, 345-359 (2016).

15. Haraway, D. Situated knowledges: the science question in feminism and the privilege of partial perspective. Fem. Stud. 14, 575-589 (1988).

16. Tengö, M. et al. Weaving knowledge systems in IPBES, CBD and beyond-lessons learned for sustainability. Curr. Opin. Environ. Sustain. 26-27, 17-25 (2017)

17. Nielsen, W. et al. Gender diversity leads to better science. Proc. Natl Acad. Sci. USA 114, 1740-1742 (2017).

18. Greenwood, D. \& Levin, M. Introduction to Action Research. Introduction to Action Reasearch (SAGE Publications, 2007).

19. Pohl, C. et al. Researchers' roles in knowledge co-production: experience from sustainability research in Kenya, Switzerland, Bolivia and Nepal. Sci. Public Policy 37, 267-281 (2010).

20. Harvey, B., Cochrane, L. \& Van Epp, M. Charting knowledge co-production pathways in climate and development. Environ. Policy Gov. 29, 107-117 (2019).

21. Hurlbert, M. \& Gupta, J. The split ladder of participation: a diagnostic, strategic, and evaluation tool to assess when participation is necessary. Environ. Sci. Policy 50, 100-113 (2015).

22. Nel, J. L. et al. Knowledge co-production and boundary work to promote implementation of conservation plans. Conserv. Biol. 30, 176-188 (2016).
23. Reed, M. S. et al. Who's in and why? A typology of stakeholder analysis methods for natural resource management. J. Environ. Manag. 90, 1933-1949 (2009)

24. Bodin, Ö., Crona, B. \& Ernstson, H. Social networks in natural resource management: what is there to learn from a structural perspective? Ecol. Soc. 11, r2 (2006).

25. Brandt, F., Josefsson, J. \& Spierenburg, M. Power and politics in stakeholder engagement: farm dweller (in)visibility and conversions to game farming in South Africa. Ecol. Soc. 23, 32 (2018).

26. Mobjörk, M. Consulting versus participatory transdisciplinarity: a refined classification of transdisciplinary research. Futures 42, 866-873 (2010).

27. Wittmayer, J. M. \& Schäpke, N. Action, research and participation: roles of researchers in sustainability transitions. Sustain. Sci. 9, 483-496 (2014).

28. Reed, M. S., Stringer, L. C., Fazey, I., Evely, A. C. \& Kruijsen, J. H. J. Five principles for the practice of knowledge exchange in environmental management. J. Environ. Manag. 146, 337-345 (2014).

29. Gaventa, J. Finding the spaces for change: a power analysis. IDS Bull. 37, 23-33 (2006).

30. Popa, F., Guillermin, M. \& Dedeurwaerdere, T. A pragmatist approach to transdisciplinarity in sustainability research: from complex systems theory to reflexive science. Futures 65, 45-56 (2015).

31. Polk, M. Transdisciplinary co-production: designing and testing a transdisciplinary research framework for societal problem solving. Futures 65, 110-122 (2015).

32. Bednarek, A. T. et al. Boundary spanning at the science-policy interface: the practitioners' perspectives. Sustain. Sci. 13, 1175-1183 (2018).

33. Cvitanovic, C., Löf, M. F., Norström, A. V. \& Reed, M. S. Building university-based boundary organisations that facilitate impacts on environmental policy and practice. PLOS ONE 13, e0203752 (2018).

34. Hahn, T., Olsson, P., Folke, C. \& Johansson, K. Trust-building, knowledge generation and organizational innovations: the role of a bridging organization for adaptive comanagement of a wetland landscape around Kristianstad, Sweden. Hum. Ecol. 34, 573-592 (2006).

35. Miller, T. R. et al. The future of sustainability science: a solutions-oriented research agenda. Sustain. Sci. 9, 239-246 (2014).

36. Wiek, A. Challenges of transdisciplinary research as interactive knowledge generation - experiences from transdisciplinary case study research. GAIA - Ecol. Perspect. Sci. Soc. 16, 52-57 (2007).

37. Leach, M. et al. Local disease-ecosystem-livelihood dynamics: reflections from comparative case studies in. Africa. Philos. Trans. Royal Soc. B 372, 20160163 (2017).

38. Earl, S., Carden, F. \& Smutylo, T. Outcome Mapping: Building Learning and Reflection into Development Programs (IDRC, 2001).

39. Moser, S. C. Can science on transformation transform science? Lessons from co-design. Curr. Opin. Environ. Sustain. 20, 106-115 (2016).

40. Wiesmann, U. et al. in Handbook of Transdisciplinary Research (eds Hadorn, G. H. et al.) 433-441 (Springer, 2008).

41. Leach, M., Stirling, A. C. \& Scoones, I. C. Dynamic Sustainabilities (Routledge, 2010).

42. Carpenter, S. R., Folke, C., Scheffer, M. \& Westley, F. Resilience: accounting for the noncomputable. Ecol. Soc. 14, 13 (2009).

43. Archibald, T., Sharrock, G., Buckley, J. \& Cook, N. Assumptions, conjectures, and other miracles: the application of evaluative thinking to theory of change models in community development. Eval. Program Plan. 59, 119-127 (2016).

44. Reid, R. S. et al. Evolution of models to support community and policy action with science: balancing pastoral livelihoods and wildlife conservation in savannas of East Africa. Proc. Natl Acad. Sci. USA 113, 4579-4584 (2016)

45. Dilling, L. \& Lemos, M. C. Creating usable science: opportunities and constraints for climate knowledge use and their implications for science policy. Glob. Environ. Change 21, 680-689 (2011).

46. Sarkki, S. et al. Adding 'iterativity' to the credibility, relevance, legitimacy: a novel scheme to highlight dynamic aspects of science-policy interfaces. Environ. Sci. Policy 54, 505-512 (2015).

47. Steyaert, P. \& Jiggins, J. Governance of complex environmental situations through social learning: a synthesis of SLIM's lessons for research, policy and practice. Environ. Sci. Policy 10, 575-586 (2007).

48. Wall, T. U., Meadow, A. M. \& Horganic, A. Developing evaluation indicators to improve the process of coproducing usable climate science. Weather Clim. Soc. 9, 95-107 (2017).

49. Meagher, L. R. \& Martin, U. Slightly dirty maths: the richly textured mechanisms of impact. Res. Eval. 26, 15-27 (2017).

50. Walter, A. I., Helgenberger, S., Wiek, A. \& Scholz, R. W. Measuring societal effects of transdisciplinary research projects: design and application of an evaluation method. Eval. Program Plan. 30, 325-338 (2007).

51. Klein, J. T. Evaluation of interdisciplinary and transdisciplinary research. Am. J. Prev. Med. 35, S116-S123 (2008).

52. Wickson, F. \& Carew, A. L. Quality criteria and indicators for responsible research and innovation: learning from transdisciplinarity. J. Responsible Innov. 1, 254-273 (2014). 
53. Belcher, B. M., Rasmussen, K. E., Kemshaw, M. R. \& Zornes, D. A. Defining and assessing research quality in a transdisciplinary context. Res. Eval. 25, 1-17 (2016).

54. Hansson, S. \& Polk, M. Assessing the impact of transdisciplinary research the usefulness of relevance, credibility, and legitimacy for understanding the link between process and impact. Res. Eval. 27, 132-144 (2018).

55. Posner, S. M., McKenzie, E. \& Ricketts, T. H. Policy impacts of ecosystem services knowledge. Proc. Natl Acad. Sci. USA 113, 1760-1765 (2016)

56. Lebel, J. \& McLean, R. A better measure of research from the global south. Nature 559, 23-26 (2018).

57. Phillipson, J., Lowe, P., Proctor, A. \& Ruto, E. Stakeholder engagement and knowledge exchange in environmental research. J. Environ. Manag. 95, 56-65 (2012)

58. Wiek, A., Talwar, S., O'Shea, M. \& Robinson, J. Toward a methodological scheme for capturing societal effects of participatory sustainability research. Res. Eval. 23, 117-132 (2014)

59. Pitt, R. et al. Wrestling with the complexity of evaluation for organizations at the boundary of science, policy, and practice. Conserv. Biol. 32, 998-1006 (2018).

60. Greenhalgh, T., Raftery, J., Hanney, S. \& Glover, M. Research impact: a narrative review. BMC Med. 14, 78 (2016).

61. Wolf, B., Lindenthal, T., Szerencsits, M., Holbrook, J. B. \& He $\beta$, J. Evaluating research beyond scientific impact: how to include criteria for productive interactions and impact on practice and society. Gaia 22, 104-114 (2013).

62. Barreteau, O., Bots, P. W. G. \& Daniell, K. A. A framework for clarifying 'participation' in participatory research to prevent its rejection for the wrong reasons. Ecol. Soc. 15, 1 (2010).

63. Tobias, S., Ströbele, M. F. \& Buser, T. How transdisciplinary projects influence participants' ways of thinking: a case study on future landscape development. Sustain. Sci. 14, 405-419 (2019).

64. Jahn, T. \& Keil, F. An actor-specific guideline for quality assurance in transdisciplinary research. Futures 65, 195-208 (2015).

65. Brisolara, S. The history of participatory evaluation and current debates in the field. New Dir. Eval. 1998, 25-41 (1998).

66. Gray, S., Chan, A., Clark, D. \& Jordan, R. Modeling the integration of stakeholder knowledge in social-ecological decision-making: benefits and limitations to knowledge diversity. Ecol. Modell. 229, 88-96 (2012).

67. Yamineva, Y. Lessons from the Intergovernmental Panel on Climate Change on inclusiveness across geographies and stakeholders. Environ. Sci. Policy 77, 244-251 (2017).

68. Woolrych, R. \& Sixsmith, J. Placing well-being and participation within processes of urban regeneration. Int. J. Public Sect. Manag. 26, 216-231 (2013).

69. Schulz, A. J., Israel, B. A. \& Lantz, P. Instrument for evaluating dimensions of group dynamics within community-based participatory research partnerships. Eval. Program Plan. 26, 249-262 (2003).

70. Bednarek, A. T., Shouse, B., Hudson, C. G. \& Goldburg, R. Science-policy intermediaries from a practitioner's perspective: the Lenfest Ocean Program experience. Sci. Public Policy 43, 291-300 (2016).

71. Wyborn, C. et al. Understanding the impacts of research synthesis. Environ. Sci. Policy 86, 72-84 (2018).

72. Chowdhury, G., Koya, K. \& Philipson, P. Measuring the impact of research: lessons from the UK's research excellence framework 2014. PLOS ONE 11, e0156978 (2016).

73. Mayne, J. Contribution analysis: coming of age? Evaluation 18, 270-280 (2012).

74. Patton, M. Q. Developmental Evaluation: Applying Complexity Concepts to Enhance Innovation and Use (Guilford Press, 2011).

75. Alcamo, J. Evaluating the impacts of global environmental assessments. Environ. Sci. Policy 77, 268-272 (2017)

76. Olsen, S. B., Page, G. G. \& Ochoa, E. The Analysis of Governance Responses to Ecosystem Change: A Handbook for Assembling a Baseline LOICZ Reports and Studies No. 34 (LOICZ, 2009).

77. Österblom, H., Jouffray, J.-B., Folke, C. \& Rockström, J. Emergence of a global science-business initiative for ocean stewardship. Proc. Natl Acad. Sci. USA 114, 9038-9043 (2017).

78. Westley, F. et al. Tipping toward sustainability: emerging pathways of transformation. Ambio 40, 762-780 (2011)

79. Geels, F. W. Technological transitions as evolutionary reconfiguration processes: a multi-level perspective and a case-study. Res. Policy 31, 1257-1274 (2002).

80. Moore, M. et al. Studying the complexity of change: toward an analytical framework for understanding deliberate social-ecological transformations. Ecol. Soc. 19, 54 (2014).

81. Abson, D. J. et al. Leverage points for sustainability transformation. Ambio 46, 30-39 (2017)

82. Galaz, V., Leach, M. \& Scoones, I. in One Health: Science, Politics and Zoonotic Disease in Africa (ed. Bardosh, K.) 21-37 (Routledge, 2016).
83. van der Hel, S. Science for change: a survey on the normative and political dimensions of global sustainability research. Glob. Environ. Change 52, 248-258 (2018).

84. Gibbons, M. et al. The New Production of Knowledge: The Dynamics of Science and Research in Contemporary Societies (Sage, 1994).

85. Funtowicz, S. O. \& Ravetz, J. R. in Perspectives on Ecological Integrity (eds Westra, L. \& Lemons, J.) 146-161 (Springer, 1995).

86. Lubchenco, J. Entering the century of the environment: a new social contract for science. Science 279, 491-497 (1998).

87. Leemans, R. The lessons learned from shifting from global-change research programmes to transdisciplinary sustainability science. Curr. Opin. Environ. Sustain. 19, 103-110 (2016).

88. Lewin, K. Action research and minority problems. J. Soc. Issues 2, 34-46 (1946).

89. Checkland, P. Soft systems methodology: a thirty year retrospective. Syst. Res. Behav. Sci. 17, 11-58 (2000).

90. Holling, C. Adaptive Environmental Assessment and Management (John Wiley \& Sons, 1978).

91. Brown, L. \& Tandon, R. Ideology and political economy in inquiry: action research and participatory research. J. Appl. Behav. Sci. 19, 277-294 (1983).

92. Ostrom, E. Crossing the great divide: Coproduction, synergy, and development. World Dev. 24, 1073-1087 (1996)

93. Watson, V. Co-production and collaboration in planning - the difference. Plan. Theory Pract. 15, 62-76 (2014).

94. Clark, W. C. \& Dickson, N. M. Sustainability science: the emerging research program. Proc. Natl Acad. Sci. USA 100, 8059-8061 (2003).

95. Lemos, M. C. \& Morehouse, B. J. The co-production of science and policy in integrated climate assessments. Glob. Environ. Change 15, 57-68 (2005).

96. Jasanoff, S. in States of Knowledge: The Co-Production of Science and Social Order (ed. Jasanoff, S.) 1-12 (Routledge, 2004).

97. Miller, C. A. \& Wyborn, C. Co-production in global sustainability: histories and theories. Environ. Sci. Policy https://doi.org/10.1016/j. envsci.2018.01.016 (2018).

98. van Kerkhoff, L. et al. Towards future-oriented conservation: managing protected areas in an era of climate change. Ambio 48, 699-713 (2019).

99. Busilacchi, S., Butler, J., Van Putten, I., Maru, Y. \& Posu, J. Asymmetrical development across transboundary regions: the case of the Torres Strait Treaty Region (Australia and Papua New Guinea). Sustainability 10, 4200 (2018).

100. Mitchell, M. G. E. et al. The Montérégie Connection: linking landscapes, biodiversity, and ecosystem services to improve decision making. Ecol. Soc. 20, 15 (2015).

\section{Acknowledgements}

A.V.N. received support by the Swedish Research Council Formas (grant number 201701326) and the GRAID programme at SRC. M.F.L. received support by the foundation BalticSea2020 and the Stockholm University Baltic Sea Centre. S.W. received support by the Swedish Research Council Formas (mobility starting grant 2017-01631). H.Ö. received support from the Walton Family Foundation (grants 2017-693 and 2018-1371), The David and Lucile Packard Foundation (grants 2017-66205 and 2019-68336), and the Gordon and Betty Moore Foundation (grants GBMF5668.01 and GBMF5668.02). R.B. received support from the South African Research Chairs Initiative (SARChI) of the Department of Science and Technology and National Research Foundation of South Africa (grant 98766); the GRAID programme at SRC; and the Swedish Research Council (grant 621-2014-5137). M.-F.L. received support by the Swiss Academy of Sciences (SCNAT) and the Chinese Academy of Sciences (CAS). B.M.C. received support from the CGIAR Trust Fund and through bilateral funding agreements. This research contributes to the Program on Ecosystem Change and Society (www.pecs-science.org).

\section{Author contributions}

The design, development and writing of the manuscript were co-led by authors A.V.N. C.C., M.F.L., C.W. and S.W. The work was coordinated by A.V.N. All authors wrote and commented on the manuscript.

\section{Competing interests}

The authors declare no competing interests.

\section{Additional information}

Supplementary information is available for this paper at https://doi.org/10.1038/ s41893-019-0448-2.

Correspondence should be addressed to A.V.N.

Reprints and permissions information is available at www.nature.com/reprints,

Publisher's note Springer Nature remains neutral with regard to jurisdictional claims in published maps and institutional affiliations.

(c) Springer Nature Limited 2020 